\title{
Using Copulas for Modeling Dependence in Wind Power
}

\author{
Ayşe Metin Karakaş \\ Department of Statistic, Faculty of Art and Sciences, \\ Bitlis Eren University, Bitlis, Turkey. \\ Email: aysekarakas5767 [AT] gmail.com
}

\begin{abstract}
Wind power is clean and renewable source of energy in all countries and circles. Moreover, wind power is one of the world's largest and most accessible sources of renewable energy. In this paper, marginal distributions were fitted to each of the variables and to examine the relationship between wind speed of Elazig, Bitlis and Van with COPULA method. The results show that there is a weak dependence between wind speed of Elazig, Bitlis and Van.
\end{abstract}

Keywords-- Wind Speed; COPULA Method; Marginal Modeling.

\section{INTRODOUCTION}

The wind is a clean, free, and readily available renewable energy source. Each day, around the world, wind turbines are taking the wind's power and transforming it to electricity. This source of power generation moves an increasingly significant role in the way we power our world.

[1] investigated stochastic dependencies of wind speed for a large data set of German on- and offshore weather stations and discover that these dependencies not become to be extremely nonlinear but constant over time, usage copula theory, they describe the value at risk of energy generation for established allocation sets of wind farms and reproduce optimum allocation plans. They discover that the optimized allocation of wind farms may substantially balance the full wind energy suppling on daily as well as hourly frequency. [2] submitted European wind power samples which are produced from the modeled stochastic process, under the prior case of a modeled perfect market environment, wind power effects send out decisions and for this reason leads to varieties in power equilibriums. Stochastic power equilibriums are applied in a comprehensive model of the European electricity network, based on the formed samples and lastly, is used to a Monte Carlo method describe power flows and probabilities in the system.

[3] taken the problem of collecting wind power, submitted here, is to refrain the assumption of extreme values of correlation, point perfect dependence or perfect independence of the generation and approve secondary values of correlation, which they debate is of particular interest for small-scale siting analysis, where the ripples of wind power production influence the capacity value or the size of energy storage. They provide a formulation that is based on the integration of the joint probability density function (PDF) of the wind power, they prepare this PDF by means of copula theory in order to deal with the related representation of the marginal PDFs and they define the PDF of wind power and the associated duration curve.

[4] said the increasing influence of renewable distributed generation in power systems requires the modeling of this stochastic construction in operation and organizing studies, an integration study of photovoltaic and wind turbines, spreaded in a distribution network, investigated based on the stochastic modeling using Archimedean copulas as a new effective instrument.

[5] submitted a review of the potential and utilization of the renewable energy sources in Turkey.

[6] indicated that wind energy source isn't efficiently used in Turkey and how the using of wind energy potential, said some general report for regarding political construction and the without support mechanism of Turkey, given a comparison between some advanced countries and Turkey and said that energy planning and management are essential to support wind energy which has a vital significance for the growth and future of Turkey.

[7] said wind energy utilization in Turkey, sharply increased throughout world and reported Turkey has an abundance of wind energy sources.

In this study, we evaluated dependence these wind power variables revealed that wind speed of Bitlis, Elaziğ and Van has weak dependence. Hence these pairs were used for modelling dependence by employing types of copulas. For the marginal modelling, the results of probability distributions fitting to these wind power variables indicated that the wind speed of Bitlis, Elazı̆̆ and Van time series Lognormal and Gamma distribution. 


\section{MATERIAL AND METHOD}

\subsection{Copula Functions}

The copula function is suggested to measure dependence of multivariate variables. Based on the famous Sklar's theorem in Sklar (1959), copulas give to put in place the efficient idea of splitting the description of a multivariate model into two parts: the marginal distributions on one side, the dependence structure (copula) on the other part. Let $X$ and $Y$ be random variables with continuous distribution functions $F_{X}$ and $F_{Y}$, which are uniformly distributed on the interval [0,1]. Then, there is a copula such that for all $x, y \in R$,

$$
F_{X Y}(X, Y)=C\left(F_{X}(X), F_{Y}(Y) .\right.
$$

The copula $C$ for $(X, Y)$ is the joint distribution function for the pair $F_{X}(X), F_{Y}(Y)$ provided $F_{X}$ and $F_{Y}$ continuous. The joint probability density of the variables $X$ and $Y$ is obtained from the copula density $(u, v)=\frac{\partial^{2} C(u, v)}{\partial u \partial v}$, as follows:

$$
f_{x y}(x, y)=c(u, v) f_{x}(\mathrm{x}) f_{y}(y),
$$

where $f_{x}(\mathrm{x})$ and $f_{y}(y)$ are the marginal densities of the random variables $X$ and $Y$. According to Sklar (1959) an $\mathrm{n}$-dimensional joint distribution can be dissociated into its n-univariate marginal distributions and an $\mathrm{n}$-dimensional copula. In the widening of Sklar's theorem to continuous conditional distributions, it isindicates that the lower (left) and upper (right) tail dependence of two random variables is given for the copula as:

$$
\begin{aligned}
\lambda_{l}=\lim _{u \rightarrow 0} P\left(\mathrm{~F}_{x}(x) \leq u \mid F_{y}(x) \leq u\right)=\lim _{u \rightarrow 0} C(u, u) / u \\
\quad \lambda_{u}=\lim _{u \rightarrow 1} P\left(\mathrm{~F}_{x}(x)>\mathrm{u} \mid F_{y}(x)>u\right)=\lim _{u \rightarrow 1} 1-2 u-C(u, u) / 1-u
\end{aligned}
$$

where $\lambda_{l}$ and $\lambda_{u} \in[0,1][9-10-11-12-13-14-15-16-17-18-19-20-21]$.

\subsection{Copula Models}

\section{Archimedean Copulas}

Since they are easily obtained depending on the single variable generator function, these copula families are often used in practice. Genest and Mackay (1985) one of the interesting properties of Archimedean copulas is that they are easily related to dependence measures.

Gumbel Copula: Copula is described with the help of generator function $\phi(t)=(-\ln t)^{\theta}, \theta \geq 1$;

$$
C_{\theta}(u, v)=\exp \left(-\left[(-\ln u)^{\theta}+(-\ln v)^{\theta}\right]^{1 / \theta}\right)
$$

where $\theta$ is the copula parameter restricted to $[1, \infty)$.

Clayton Copula: Copula is described with the help of generator function $\phi(t)=\frac{t^{-\theta}-1}{\theta}$,

$$
C_{\theta}(u, v)=\left(u^{-\theta}+v^{-\theta}-1\right) .
$$

where $\theta$ is the copula parameter restricted to $(0, \infty)$.

Frank Copula: Copula is described w with the help of generator function; $\phi(t)=-\ln \frac{-e^{-\theta t}-1}{e^{-\theta}-1}$;

$$
C_{\theta}(u, v)=-\frac{1}{\theta} \ln \left(1+\frac{\left(e^{-\theta u}-1\right)\left(e^{-\theta v}-1\right)}{\left(e^{-\theta}-1\right)}\right)
$$

where $\theta$ is the copula parameter restricted to $(0, \infty)$.

Joe Copula: Copula is described with the help of generator function; $\phi(t)=-\ln \left[1-(1-t){ }^{\theta}\right]$

$$
C_{\theta}(u, v)=1-\left[(1-u)^{\theta}+(1-v)^{\theta}-(1-u)^{\theta}(1-v)^{\theta}\right]^{1 / \theta}
$$


where $\theta$ is the copula parameter restricted to $[1, \infty)$.

The BB1 Copula (Clayton-Gumbel): Copula is given by

$$
C(u, v)=1-\left(u_{1}^{-\theta}+u_{2}^{-\theta}-u_{1}^{-\theta} u_{2}^{-\theta}\right)^{1 / \theta}
$$

with $\theta \in[1, \infty)$.

The BB6 Copula (Joe-Gumbel): Copula is

$$
C\left(u_{1}, u_{2}, \theta, \delta\right)=1-\left(1-\exp \left\{-\left[\left(-\log \left(1-u_{1}^{-\theta}\right)\right)^{\delta}+\left(-\log \left(1-u_{2}{ }^{-\theta}\right)\right)^{\delta}\right]^{\frac{1}{\delta}}\right\}\right)^{\frac{1}{\theta}}
$$

with $\theta \in[1, \infty) \cap \delta \in[1, \infty)$.

The BB7 (Joe-Clayton): Copula is given by

$$
C\left(u_{1}, u_{2}, \theta, \delta\right)=1-\left(1-\left[\left(1-\bar{u}_{1}^{\theta}\right)^{-\delta}+\left(1-\left[\left(1-\bar{u}_{2}^{\theta}\right)^{-\delta}-1\right]^{\frac{1}{\delta}}\right)^{\frac{1}{\theta}}\right.\right.
$$

with $\theta \in[1, \infty) \cap \delta \in[0, \infty)$.

The BB8 (Frank-Joe): Copula is

$$
C\left(u_{1}, u_{2}, \theta, \delta\right)=\frac{1}{\delta}\left(1-\left[1-\frac{1}{1-(1-\delta)}\left(1-\left(1-\delta u_{1}\right)^{\theta}\right)\left(1-\left(1-\delta u_{2}\right) \theta\right)\right] \frac{1}{\theta}\right)
$$

with $\theta \in[1, \infty) \cap \delta \in(0,1]$.

\section{Elliptical Copulas}

Gaussian copula: The copula function can be written as;

$$
C(u, v ; \rho)=\int_{-\infty}^{\Phi^{-1}(u)} \int_{-\infty}^{\Phi^{-1}(v)} \frac{1}{2 \pi \sqrt{1-\rho^{2}}} \exp \left(\frac{2 \rho r s-r^{2}-s^{2}}{2\left(1-\rho^{2}\right)}\right) d r d s
$$

where $u=F_{Y_{1}}\left(\mathrm{y}_{1}\right), v=F_{Y_{2}}\left(\mathrm{y}_{2}\right)$ is the inverse of the standard normal distribution and $\rho$ is the general correlation coefficient.

Student t copula: Student t copula: The Student's t-copula allows for joint fat tails and an increased probability of joint extreme events compared with the Gaussian copula. This copula can be written as;

$$
C_{\rho, v}(u, v)=\int_{-\infty}^{t_{v}^{-1}(u)} \int_{-\infty}^{t_{v}^{-1}(v)} \frac{1}{2 \pi\left(1-\rho^{2}\right)^{1 / 2}}\left\{1+\frac{x^{2}-2 \rho x y+y^{2}}{v\left(1-\rho^{2}\right)}\right\}^{-(v+2) / 2} d s d t
$$

where $\rho, v$ parameters of the t copula.

\section{Survival Copulas}

Survival Copula is described

$$
C_{180}(\mathrm{u}, \mathrm{v})=\mathrm{u}+\mathrm{v}-1+\mathrm{C}(1-\mathrm{u}, 1-\mathrm{v})
$$

Then $P[X>x, Y>y]=C(\bar{F}(x), \bar{G}(y))$. The function $C$ is called the survival copula of $(X, Y)$.

\section{DATA SET}

Wind speed of Bitlis, Elazı $\breve{g}$ and Van data was obtained from Elazig general Directorate of Meteorology daily prices between 01.01.2012 - 31.12.2017. There are 2192 observations in total. Table 1 summarizes statistics of series. In table 1 
Mean value of the data are different from each other and the corresponding standard deviations are fairly different. Skewness of the wind speed of Bitlis, Elazığ and Van are positive. It is indicated that wind speed of Bitlis, Elazığ and Van are skewed right beside. The high kurtosis of Bitlis wind power series reveals that extreme value changes often occur when the tail of series distributions shows fatness. The Jarque-Bera (JB) test shows that the normality of each return series distribution is strongly rejected at 0.05 level, which means all the six index distributions are non-normal.

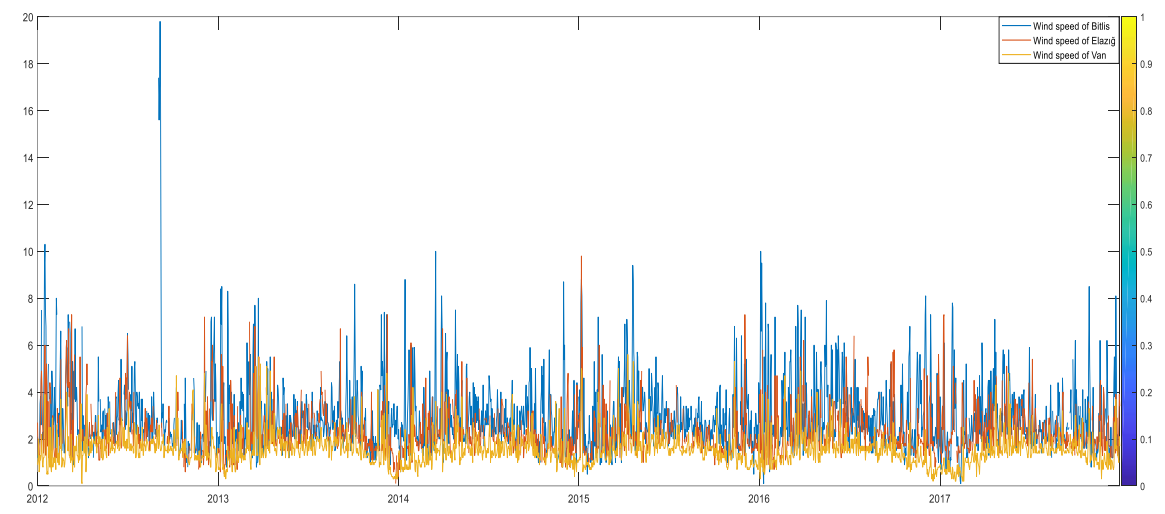

Figure 1: Wind Speed of Bitlis, Elazı̆̆ and Van change over years respectively

Table 1: Summary Statistics

\begin{tabular}{lccc}
\hline & Bitlis & Elazı ̆ & Van \\
\hline Mean & 2,963458 & 2,32570 & 1,565922 \\
Median & 2,600000 & 2,10000 & 1,500000 \\
Maksimum & 19,80000 & 9,80000 & 5,600000 \\
Minumum & 0,100000 & 0,00000 & 0,100000 \\
Std.Dev & 1,585329 & 1,02679 & 0,689136 \\
Skewness & 2,815257 & 1,77800 & 1,722892 \\
Kurtosis & 20,22551 & 4,99500 & 8,616717 \\
Jarqure Bera & 29375,32 & 30675,03 & 3695,779 \\
Probability & 0,000000 & 0,000000 & 0,00000
\end{tabular}

\section{RESULTS}

\subsection{Fitting marginal distrubutions to wind speed of Bitlis, Elazı̆̆ and Van}

Before evaluating the dependence, marginal distributions were fitted to each of the variables. For wind speed of Bitlis, Elazığ and Van, the most popular distributions were used, namely Logistic, Weibull, Gamma, Lognormal and Exponential. The probability density distribution and parameter estimates are shown Table 2 and Table 3 . In all cases, the estimates were obtained using the method of maximum likelihood. The best distribution was selected based on Akaike information criteria and Bayes information Criteria and graphical indicator. From Table 2, wind speed of Bitlis and Elazı̆g time series are best Lognormaldistribution and wind speed of Van time series is best Gamma distribution. 

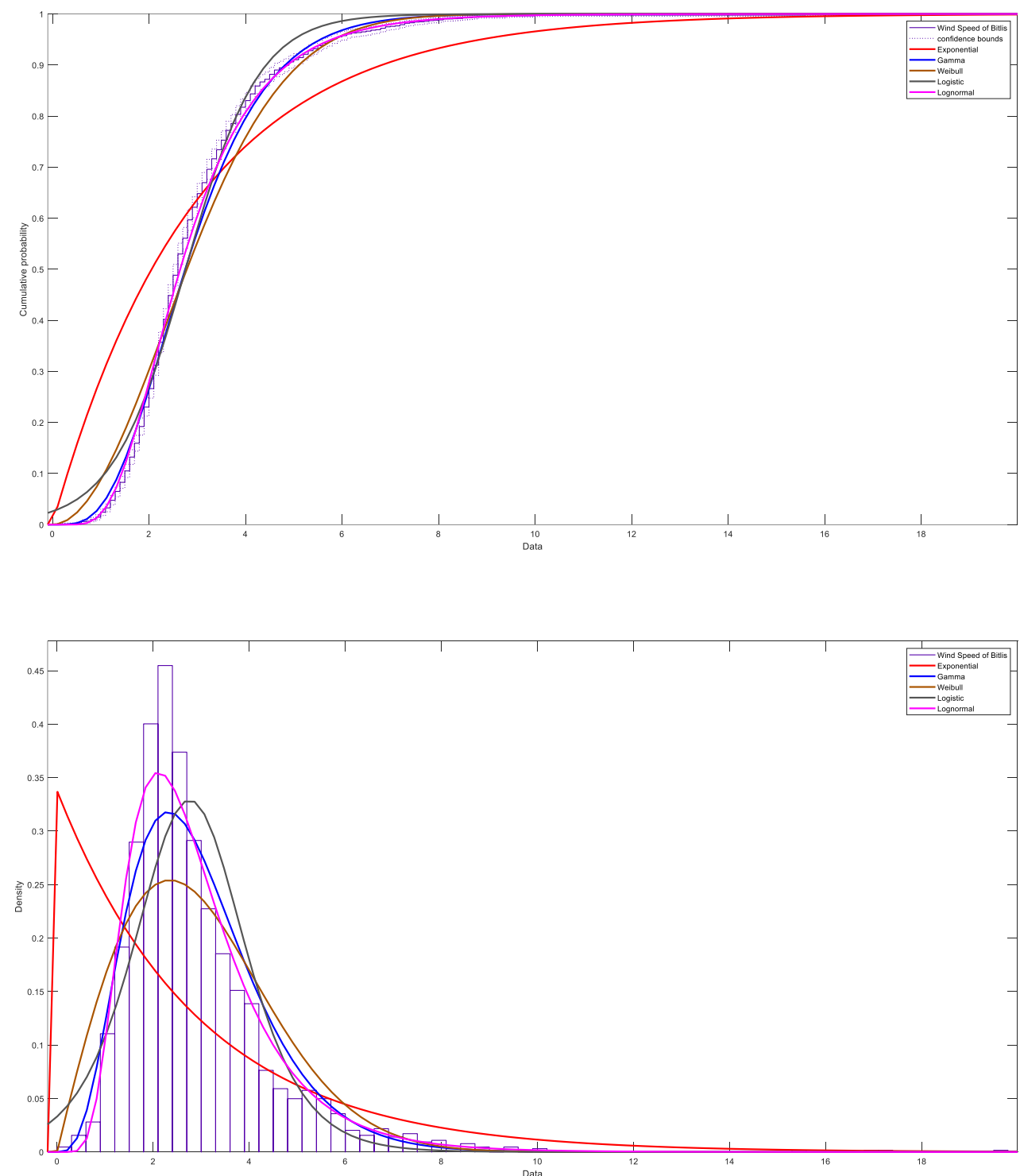

Figure2: Cumulative and Density distribution function of Logistic, Weibull, Gamma, Lognormal and Exponential Wind Speed of Bitlis, respectively 

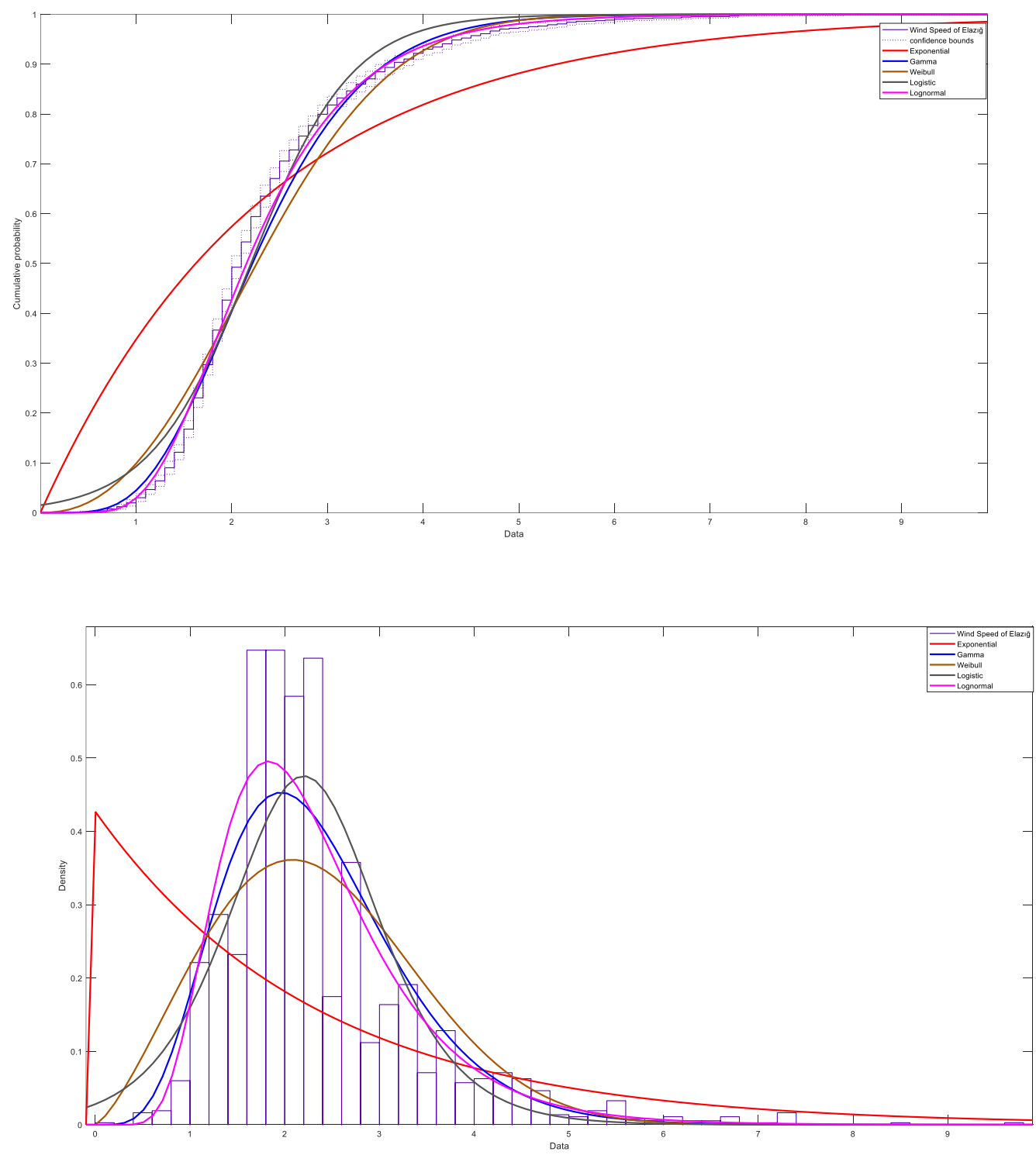

Figure3: Cumulative and Density distribution function of Logistic, Weibull, Gamma, Lognormal and Exponential Wind Speed of Elazı̆ 

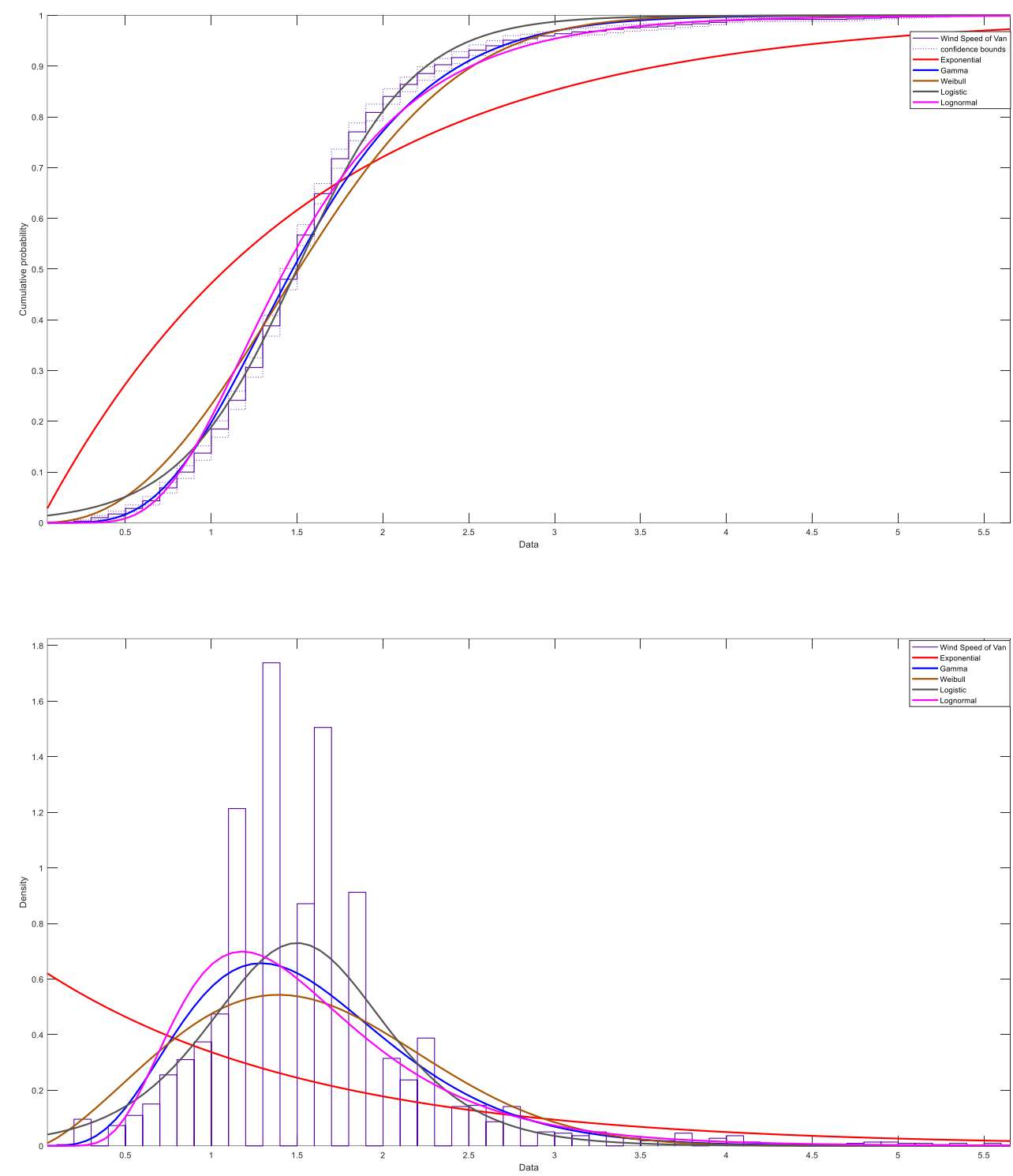

Figure4: Cumulative and Density distribution function of Logistic, Weibull, Gamma, Lognormal and Exponential Wind Speed of Van, respectively

Table 2: Performance evaluation of different probability distributions fitted to wind speed ofBitlis, Elazı $\breve{g}$ and Van

\begin{tabular}{cccccc}
\hline & Logistic & Weilbull & Gamma & Exponential & Lognormal \\
\hline Wind speed of Bitlis & & & & & \\
\hline Logl & $-3760,01$ & $-3762,46$ & $-3571,54$ & $-4464,8$ & $\mathbf{- 3 5 2 7 , 5 1}$ \\
AIC & 7524,02 & 7528,92 & 7147,08 & 8933,6 & $\mathbf{7 0 5 9 , 0 2}$ \\
BIC & 7526,702 & 7531,62 & 7149,71 & 8936,2 & $\mathbf{7 0 6 1 , 7 0}$ \\
Wind speed of Elazı & & & & & \\
Logl & $-2537,06$ & $-2564,49$ & $-2394,61$ & $-3389,15$ & $\mathbf{- 2 3 5 0 , 7 8}$ \\
AIC & 5078,12 & 5132,98 & 4793,22 & 6782,3 & $\mathbf{4 7 0 5 , 5 6}$ \\
BIC & 5080,80 & 5135,66 & 4795,90 & 6784,9 & $\mathbf{4 7 0 8 , 2 4}$ \\
Wind speed of Van & & & & & \\
Logl & $-2101,34$ & $-2191,29$ & $\mathbf{- 2 0 5 5 , 1 4}$ & $-3175,06$ & $-2091,4$ \\
AIC & 4206,68 & 4386,58 & $\mathbf{4 1 1 4 , 2 8}$ & 6354,12 & 4186,8 \\
BIC & 4209,36 & 4389,26 & $\mathbf{4 1 1 6 , 9 6}$ & 6356,80 & 4189,4 \\
\hline
\end{tabular}


Table 3: Parameters of the probability distributions fitted to wind speed of Bitlis, Elazı ̆g and Van, respectively

\begin{tabular}{|c|c|c|c|c|c|c|c|c|c|}
\hline & Logistic & & Weilbull & & Gamma & & Exponential & Lognormal & \\
\hline & $\mu$ & $\sigma$ & $\alpha$ & $\beta$ & $\alpha$ & $\beta$ & $\mu$ & $\mu$ & $\sigma$ \\
\hline Wind speed of Bitlis & 2,75705 & 0,759664 & 3,35109 & 1,979 & 4,56529 & 0,649128 & 2,96346 & 0,972855 & 0,475595 \\
\hline $\begin{array}{l}\text { Wind speed of } \\
\text { Elazı̆g }\end{array}$ & 2,20026 & 0,525591 & 2,64523 & 2,32989 & 6,11428 & 0,383028 & 2,34194 & 0,766983 & 0,40585 \\
\hline Wind speed of Van & 1,49934 & 0,385815 & 1,76498 & 2,34028 & 5,68069 & 0,275657 & 1,56592 & 0,357882 & 0,439338 \\
\hline
\end{tabular}

\subsection{Copulas for modeling dependence}

In this study, to model dependence of wind speed of Bitlis, Elazı $\breve{g}$ and Van, we used the most common single parameter Archimedean families such as the Clayton, Gumbel, Frank and Joe. Furthermore, four Archimedean copula families with two parameters, namely the Clayton-Gumbel (BB1), the Joe-Gumbel (BB6), The Joe- Clayton (BB7) and the Joe-Frank (BB8).We also used the corresponding survival copulas. In addition, we used elliptical copulas; Gaussianand Student t.In figure 5, we give raw data and transformed data, namely we used It is shown that empirical distribution functions in figure 6, 7, 8. We obtaincorrelation coefficients betweenwind speed of Bitlis and Elazı $\breve{g}$; Kendall Tau $\tau=0,201$ and Spearman Rho $\rho=0,284$, correlation coefficients between wind speed of Bitlis and Van; Kendall Tau $\tau=0,299$ and Spearman Rho $\rho=0,405$ and correlation coefficients between wind speed of Van and Elaziğ; Kendall Tau $\tau=0,266$ and Spearman Rho $\rho=0,361$. Accordingly, it is observed that the relationship of wind speed of Bitlis, Elazı̆̆ and Van are weak in the positive direction. But, it is observed that the relationship between wind speed of Bitlis and Vanis more strong than wind speed of Bitlis and Elazı̆ and Elazığ and Van. From table 4 and table 5, according to the Log 1 value, AIC and BIC criteria, it is obtained that as the relationship between wind speed of Bitlis and Elazığ are modelling by Survival BB8 copula, the relationship between wind speed of Bitlis and Van is modelling by Tawn type 1 copula and the relationship between wind speed of Elazı ğ and Van are modeling by Rotated Tawn Type 2180 degrees'copula.In table 4, the calculated tail dependence values for the pairs wind speed of Bitlis and Elazı $\breve{g}$ when $\lambda_{l}=0, \lambda_{u}=0$, symmetric tail dependency is observed in the tail of these pairs. From table 5, for the wind speed of Bitlis and Van pairs, tail dependency coefficients are $\lambda_{u}=0,33 \lambda_{l}=0$. From table 6 , for the wind speed of Elazığ and Van pairs, tail dependency coefficients are $\lambda_{u}=0 \lambda_{l}=0$, 24. According to these values, wind speed of Bitlis and Van pairs pairs have the highest upper tail dependency and wind speed of Elazığ and Van pairs pairs have the lowest upper tail dependency. In figure 9, 10,11 for each copula used, we are prioritizing for Logl value of each copula and we are shown scatter garph of the relationship between wind speed of Bitlis, Elazığ pairs, Bitlis- Van pairs and Elazığ- Van pairs, respectively. 

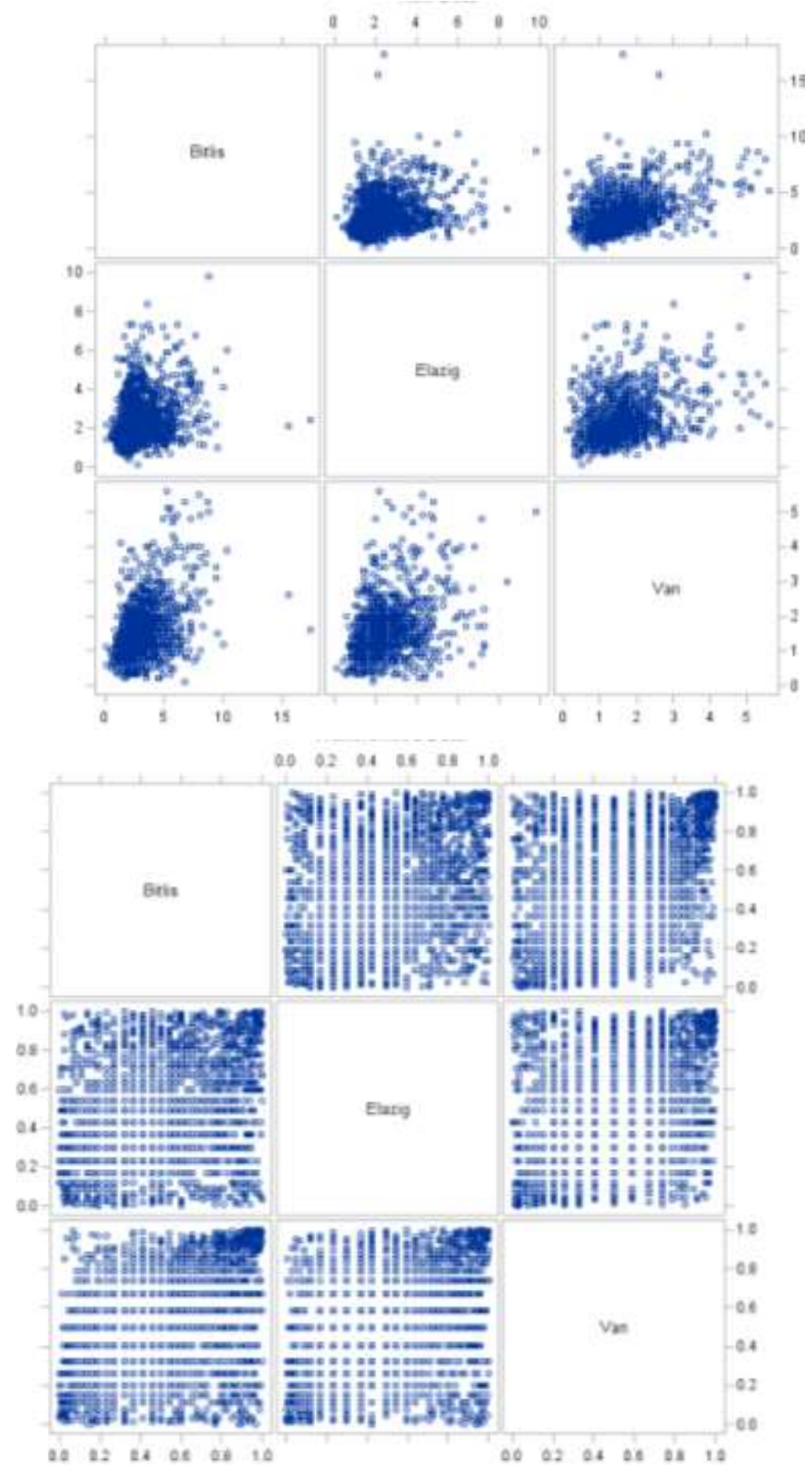

Figure 5: Raw data and Transformed data figure 

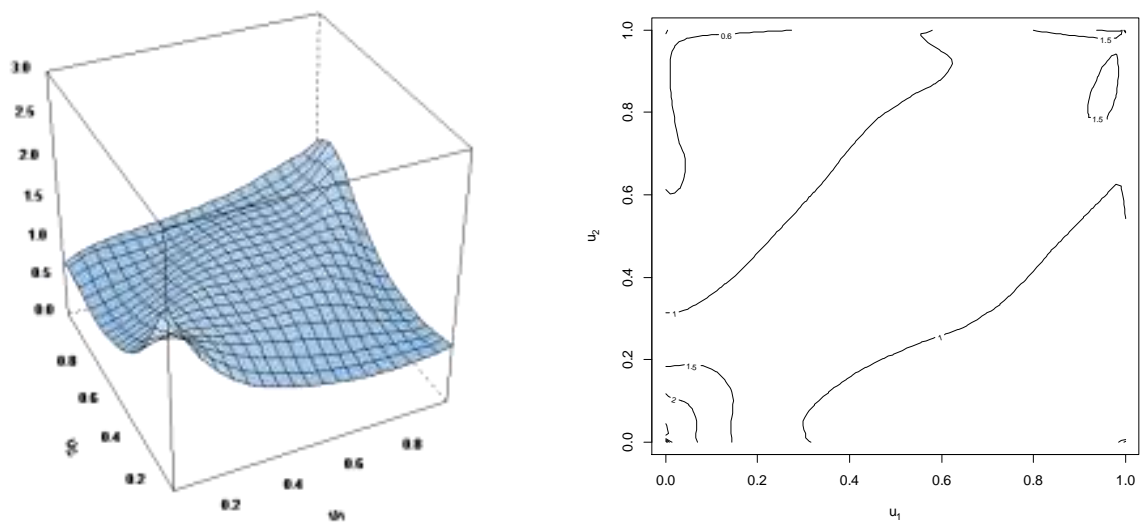

Figure 6: Three and two dimensional Kernel distrubution function of wind speed of Bitlis and Elazı ̆ respectively
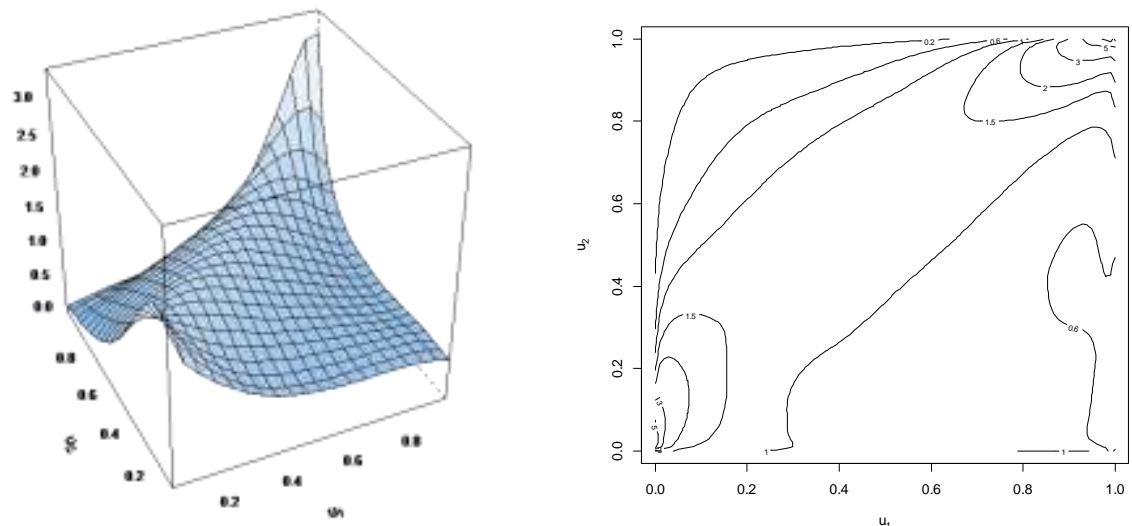

Figure 7: Three and two dimensional Kernel distribution function of wind speed of Bitlis and Van respectively
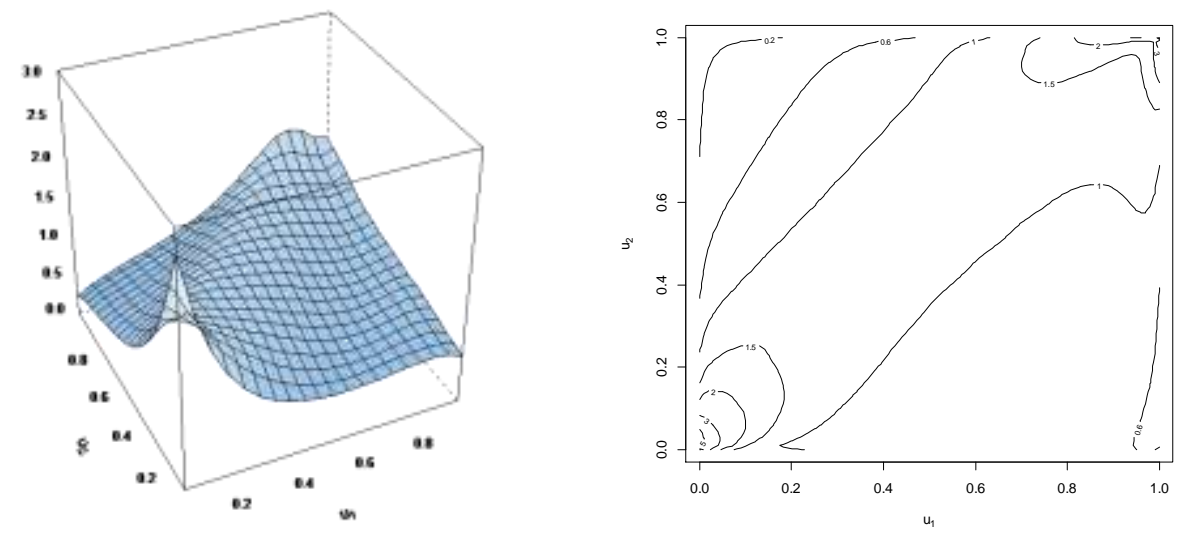

Figure 8: Three and two dimensional Kernel distribution function of wind speed of Elazı̆ and Van respectively 
Table 4: Parameters, Logl, AIC and BIC of different copulas fitted to wind speed of Bitlis and Elazı $\breve{g}$

\begin{tabular}{|c|c|c|c|c|c|c|c|c|}
\hline Family & $\theta$ & $\rho$ & $V$ & $\lambda_{u}$ & $\lambda_{l}$ & $\log L$ & AIC & BIC \\
\hline Gaussian (1) & & 0,2 & & 0 & 0 & 43,82 & $-85,63$ & $-79,94$ \\
\hline Student $\mathbf{t}$ (2) & & 0,21 & 12,78 & 0,01 & 0,01 & 49,33 & $-94,67$ & $-83,28$ \\
\hline Clayton (3) & 0,25 & & & 0 & 0,06 & 44,8 & $-87,6$ & $-81,91$ \\
\hline Gumbel (4) & 1,12 & & & 0,14 & 0 & 30,39 & $-58,78$ & $-53,08$ \\
\hline Frank (5) & 1,35 & & & 0 & 0 & 52,23 & $-102,45$ & $-96,76$ \\
\hline Joe (6) & 1,12 & & & 0,14 & 0 & 14,19 & $-26,39$ & $-20,7$ \\
\hline BB1 (7) & & 0,2 & 1,04 & 0,05 & 0,04 & 46,67 & $-89,33$ & $-77,95$ \\
\hline BB6 (8) & & 1 & 1,12 & 0,14 & 0 & 30,29 & $-56,58$ & $-45,2$ \\
\hline BB7 (9) & & 1,03 & 0,24 & 0,04 & 0,05 & 45,54 & $-87,08$ & $-75,69$ \\
\hline BB8 $(\mathbf{1 0})$ & & 6 & 0,22 & 0 & 0 & 50,56 & $-97,12$ & $-85,73$ \\
\hline Survival Clayton (13) (Clayton 180 degrees) & 0,18 & & & 0,02 & 0 & 23,25 & $-44,49$ & $-38,8$ \\
\hline Survival Gumbel(14) (Gumbel 180 degrees) & 1,15 & & & 0 & 0,17 & 47,62 & $-93,23$ & $-87,54$ \\
\hline Survival Joe(16) (Joe 180 degrees) & 1,2 & & & 0 & 0,22 & 38,63 & $-75,25$ & $-69,56$ \\
\hline Survival BB1(17)(BB1 180 degrees) & & 0,01 & 1,14 & 0 & 0,17 & 47,68 & $-91,35$ & $-79,97$ \\
\hline Survival BB6 (18) (BB6 180 degrees) & & 1 & 1,15 & 0 & 0,17 & 47,59 & $-91,17$ & $-79,79$ \\
\hline Survival BB7 (19) (BB7 180 degrees) & & 1,16 & 0,09 & 0 & 0,18 & 43,02 & $-82,04$ & $-70,66$ \\
\hline Survival BB8(20) (BB8 180 degrees) & & 1,73 & $\mathbf{0 , 8}$ & $\mathbf{0}$ & $\mathbf{0}$ & 59,77 & $-115,53$ & $-104,15$ \\
\hline Tawn type $1(\mathbf{1 0 4})$ & & 1,19 & 0,35 & 0,11 & 0 & 25,31 & $-46,62$ & $-35,23$ \\
\hline Rotated Tawn Type 1180 degrees (114) & & 1,22 & 0,35 & 0 & 0,13 & 36,41 & $-68,82$ & $-57,44$ \\
\hline Tawn type $2(204)$ & & 1,2 & 0,35 & 0,12 & 0 & 25,59 & $-47,17$ & $-35,79$ \\
\hline Rotated Tawn Type 2180 degrees (214) & & 1,25 & 0,35 & 0 & 0,14 & 41,45 & $-78,91$ & $-67,52$ \\
\hline
\end{tabular}



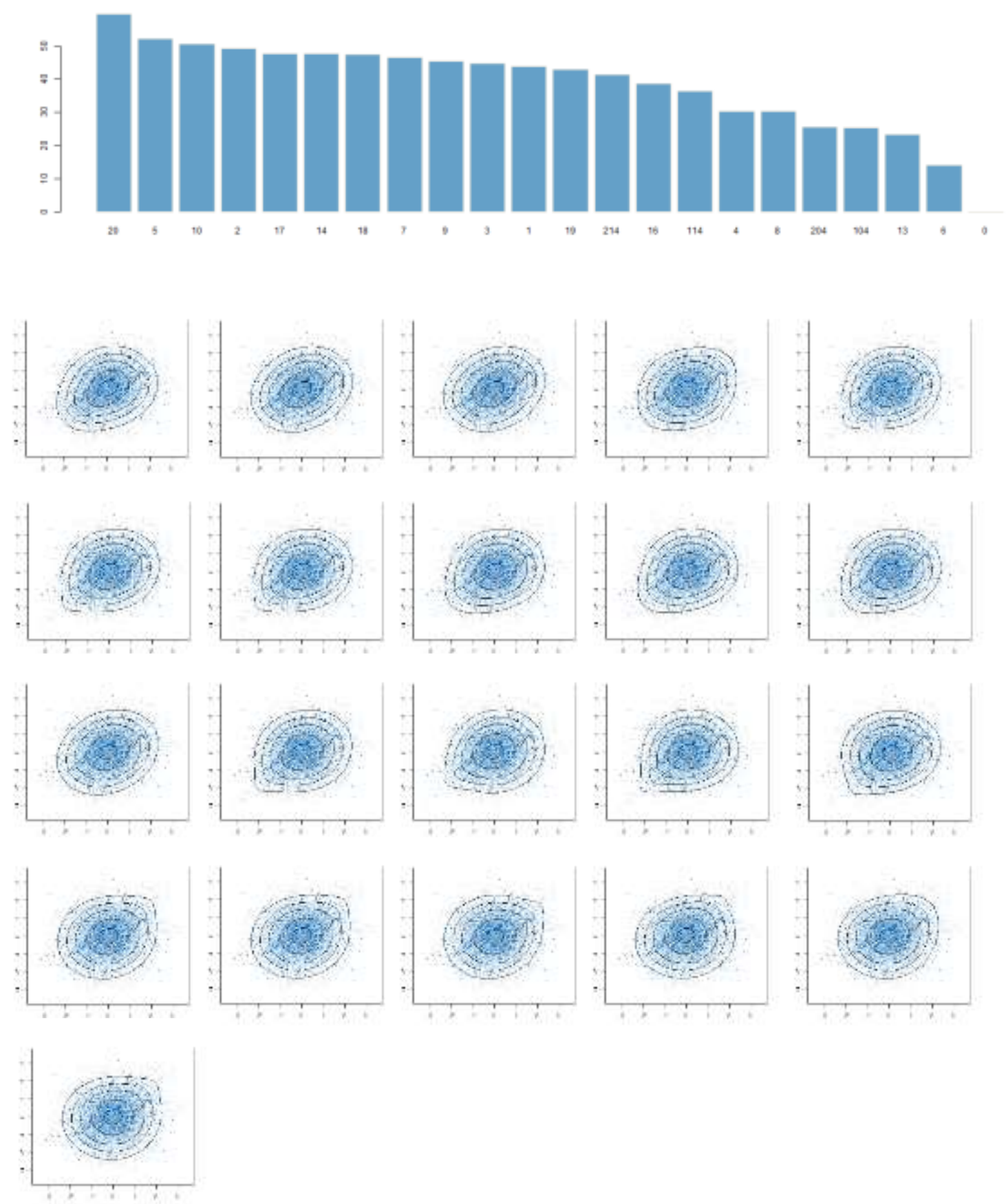

Figure 9: $\operatorname{Logl}$ of different copulas fitted to wind speed of Bitlis and Elazı $\breve{g}$, respectively. 
Table 5: Parameters, Logl, AIC and BIC of different copulas fitted to wind speed of Bitlis and Van

\begin{tabular}{|c|c|c|c|c|c|c|c|c|}
\hline Family & $\theta$ & $\rho$ & $v$ & $\lambda_{u}$ & $\lambda_{l}$ & $\log L$ & AIC & BIC \\
\hline Gaussian (1) & & 0,4 & & 0 & 0 & 186,02 & $-370,04$ & $-364,35$ \\
\hline Student t (2) & & 0,41 & 9,87 & 0,06 & 0,06 & 199,16 & $-394,33$ & $-382,94$ \\
\hline Clayton (3) & 0,45 & & & 0 & 0,22 & 116,98 & $-231,96$ & $-226,27$ \\
\hline Gumbel (4) & 1,34 & & & 0,32 & 0 & 193,02 & $-384,05$ & $-378,36$ \\
\hline Frank (5) & 2,69 & & & 0 & 0 & 191,82 & $-381,64$ & $-375,95$ \\
\hline Joe (6) & 1,46 & & & 0,39 & 0 & 159,69 & $-317,38$ & $-311,69$ \\
\hline BB1 (7) & & 0,08 & 1,3 & 0,29 & 0 & 195,59 & $-387,18$ & $-375,8$ \\
\hline BB6 (8) & & 1 & 1,34 & 0,32 & 0 & 192,98 & $-381,95$ & $-370,57$ \\
\hline BB7 (9) & & 1,36 & 0,25 & 0,33 & 0,06 & 186,21 & $-368,42$ & $-357,04$ \\
\hline BB8 (10) & & 2,44 & 0,81 & 0 & 0 & 204,82 & $-405,64$ & $-394,25$ \\
\hline $\begin{array}{c}\text { Survival Clayton (13) (Clayton } 180 \\
\text { degrees) }\end{array}$ & 0,56 & & & 0,29 & 0 & 173,46 & $-344,92$ & $-339,23$ \\
\hline $\begin{array}{c}\text { Survival Gumbel (14) (Gumbel } 180 \\
\text { degrees) }\end{array}$ & 1,31 & & & 0 & 0,3 & 152,1 & $-302,2$ & $-296,51$ \\
\hline Survival Joe (16) (Joe 180 degrees) & 1,35 & & & 0 & 0,33 & 93,91 & $-185,82$ & $-180,13$ \\
\hline Survival BB1 (17)(BB1 180 degrees) & & 0,36 & 1,14 & 0,18 & 0,16 & 192,83 & $-381,66$ & $-370,27$ \\
\hline Survival BB6 (18) (BB6 180 degrees) & & 1 & 1,31 & 0 & 0,3 & 151,97 & $-299,94$ & $-288,56$ \\
\hline Survival BB7 (19) (BB7 180 degrees) & & 1,15 & 0,48 & 0,23 & 0,17 & 187,07 & $-370,14$ & $-358,75$ \\
\hline Survival BB8 (20) (BB8 180 degrees) & & 6 & 0,38 & 0 & 0 & 184,67 & $-365,35$ & $-353,96$ \\
\hline Tawn type $1(104)$ & & 1,87 & $\mathbf{0 , 4 5}$ & $\mathbf{0 , 3 3}$ & $\mathbf{0}$ & 241,26 & $-504,52$ & $-493,13$ \\
\hline Rotated Tawn Type 1180 degrees (114) & & 1,29 & 0,48 & 0 & 0,19 & 88,87 & $-173,75$ & $-162,36$ \\
\hline Tawn type $2(204)$ & & 1,33 & 048 & 0,21 & 0 & 116,45 & $-228,89$ & $-217,51$ \\
\hline Rotated Tawn Type 2180 degrees (214) & & 1,76 & 0,43 & 0 & 0,31 & 205,65 & $-407,3$ & $-395,91$ \\
\hline
\end{tabular}



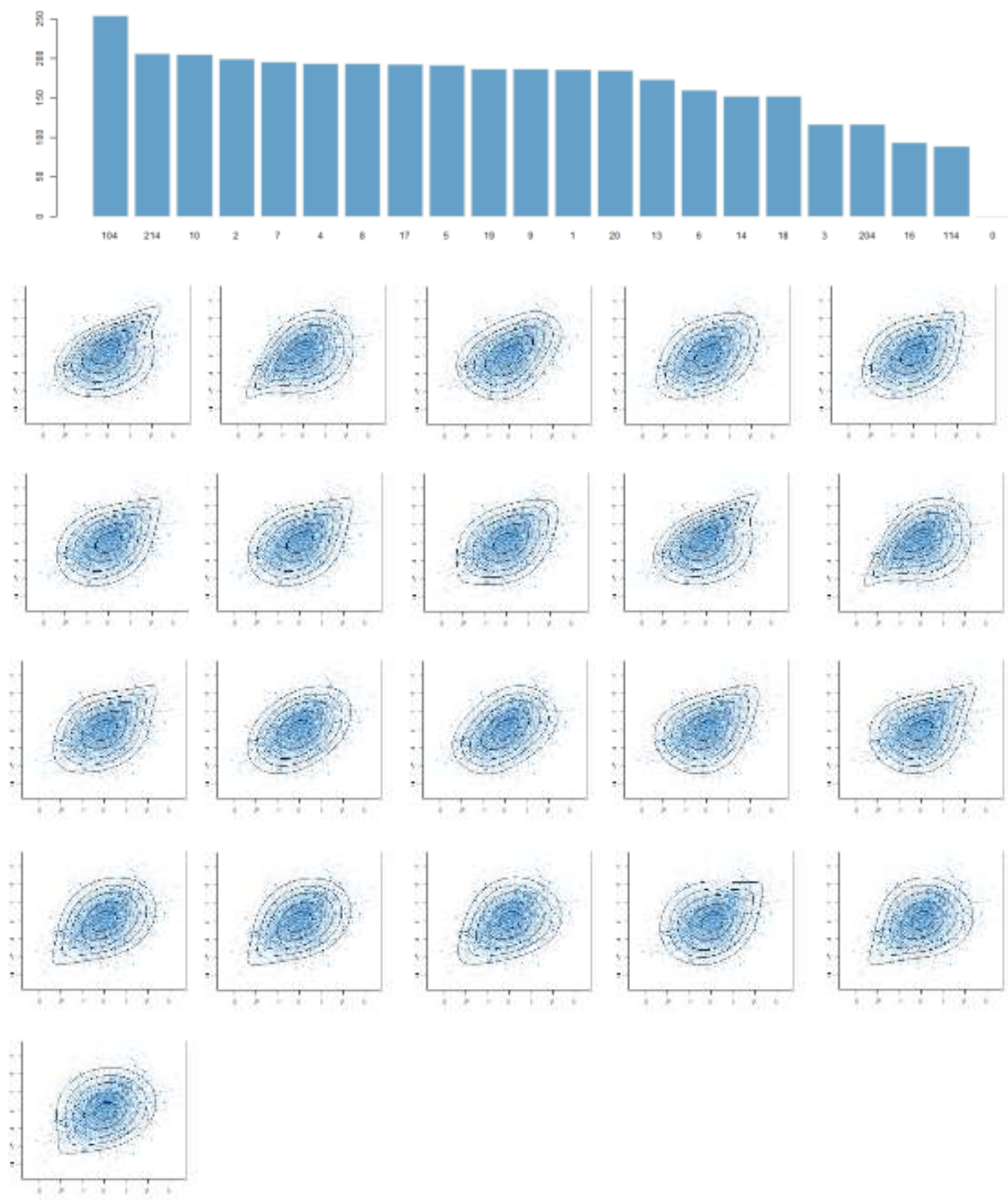

Figure 10: Logl of different copulas fitted to wind speed of Bitlis and Van, respectively. 
Table 6: Parameters, Logl, AIC and BIC of different copulas fitted to wind speed of Elazı̆̆ and Van

\begin{tabular}{|c|c|c|c|c|c|c|c|c|}
\hline Family & $\theta$ & $\rho$ & $V$ & $\lambda_{u}$ & $\lambda_{l}$ & $\log L$ & AIC & BIC \\
\hline Gaussian (1) & & 0,31 & & 0 & 0 & 108,62 & $-215,25$ & $-209,56$ \\
\hline Student $t$ (2) & & 0,31 & 12,18 & 0,02 & 0,02 & 115,21 & $-226,43$ & $-215,04$ \\
\hline Clayton (3) & 0,42 & & & 0 & 0,2 & 108,4 & $-214,8$ & $-209,11$ \\
\hline Gumbel (4) & 1,2 & & & 0,22 & 0 & 77,317 & $-152,35$ & $-146,65$ \\
\hline Frank (5) & 1,98 & & & 0 & 0 & $-109,15$ & $-216,3$ & $-210,61$ \\
\hline Joe (6) & 1,21 & & & 0,22 & 0 & 41,55 & $-81,11$ & $-75,41$ \\
\hline BB1 (7) & & 0,33 & 1,06 & 0,08 & 0,14 & 114,56 & $-225,13$ & $-213,74$ \\
\hline BB6 (8) & & 1 & 1,2 & 0,22 & 0 & 77,05 & $-150,1$ & $-138,71$ \\
\hline BB7 & & 1,06 & 0,39 & 0,08 & 0,17 & 69 & $-221,38$ & -210 \\
\hline BB8 (10) & & 6 & 0,3 & 0 & 0 & 104,42 & $-204,83$ & $-193,45$ \\
\hline Survival Clayton (13) (Clayton $180 \mathrm{deg}$ & 0,31 & & & 0,1 & 0 & 63,24 & $-124,48$ & $-118,79$ \\
\hline Survival Gumbel (14) (Gumbel 180 degrees) & 1,25 & & & 0 & 0,26 & 122,13 & $-242,25$ & $-236,56$ \\
\hline Survival Joe (16) (Joe 180 degrees) & 1,34 & & & 0 & 0,32 & 105,25 & $-208,5$ & $-202,81$ \\
\hline Survival BB1 (17)(BB1 180 degrees) & & 0,04 & 1,23 & 0 & 0,24 & & $-241,8$ & $-230,42$ \\
\hline Survival BB6 (18) (BB6 180 degrees) & & 1 & 1,25 & 0 & 0,26 & 122,1 & $-240,2$ & $-228,82$ \\
\hline Survival BB7 (19) (BB7 180 degrees) & & 1,28 & 0,16 & 0,01 & 0,28 & 118,48 & $-232,95$ & $-221,57$ \\
\hline Survival BB8 (20) (BB8 180 degrees) & & 1,84 & 0,87 & 0 & 0 & 124,63 & $-245,25$ & $-233,87$ \\
\hline Tawn type $1(\mathbf{1 0 4})$ & & 1,38 & 0,41 & 0,21 & 0 & 80,6 & $-157,2$ & $-145,81$ \\
\hline Rotated Tawn Type 1180 degrees (114) & & 1,29 & 0,41 & 0 & 0,17 & & $-158,25$ & $-146,86$ \\
\hline Tawn type $2(204)$ & & 1,25 & 0,41 & 0,15 & 0 & 55,73 & $-107,46$ & $-96,08$ \\
\hline Rotated Tawn Type 2180 degrees (214) & & 1,5 & 0,41 & $\mathbf{0}$ & 0,24 & 135,74 & $-267,48$ & $-256,1$ \\
\hline
\end{tabular}



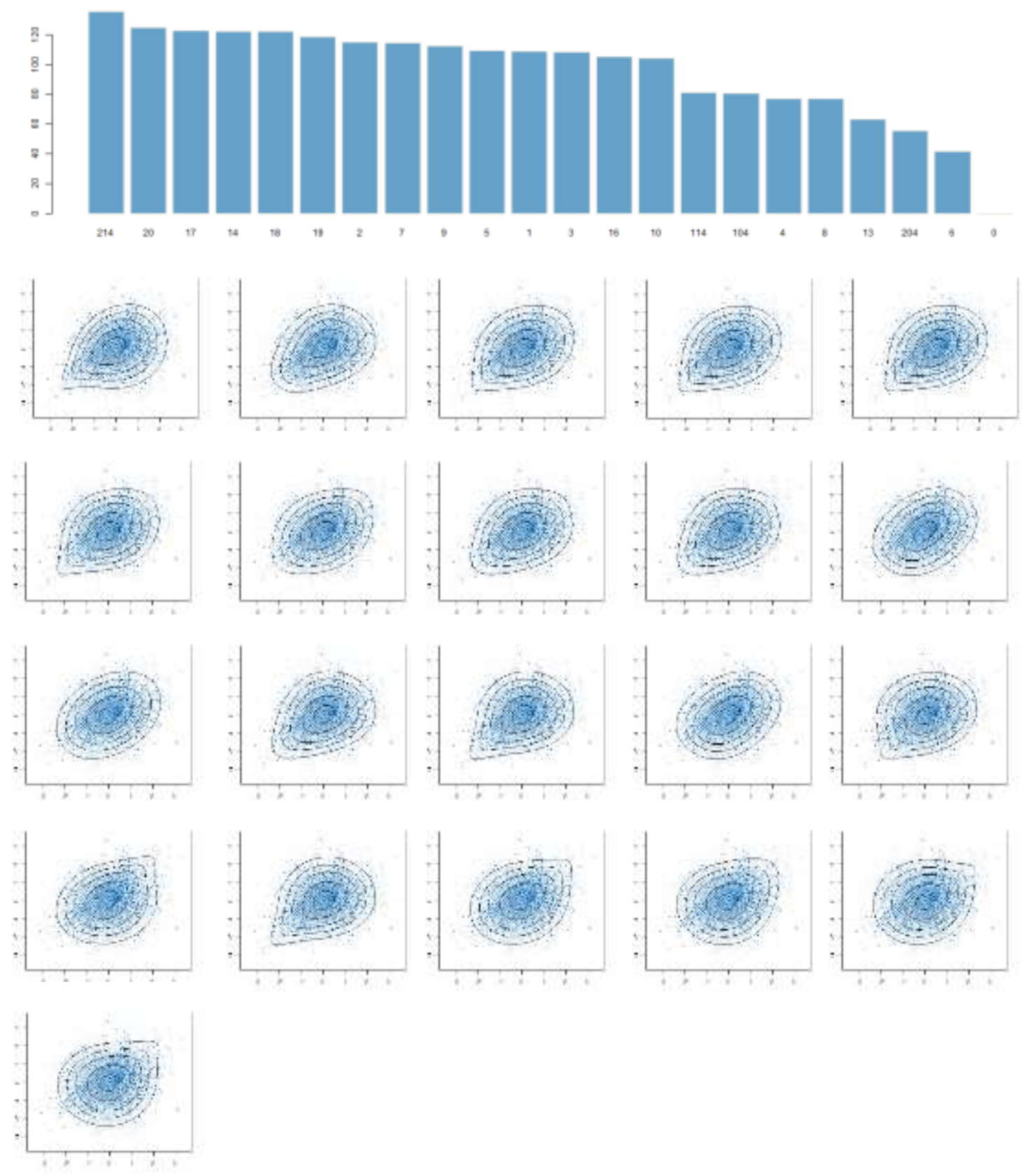

Figure 11: Logl of different copulas fitted to wind speed of Elazı̆̆ and Van, respectively.

\section{REFERENCES}

[1] Grothe, O., \& Schnieders, J. 2011. Spatial dependence in wind and optimal wind power allocation: A copulabased analysis. Energy policy, 39(9):4742-4754.

[2] Hagspiel, S., Papaemannouil, A., Schmid, M., \& Andersson, G. 2012. Copula-based modeling of stochastic wind power in Europe and implications for the Swiss power grid. Applied energy, 96: 33-44.

[3] Díaz, G., Gómez-Aleixandre, J., \& Coto, J. 2014. Statistical characterization of aggregated wind power from small clusters of generators. International Journal of Electrical Power \& Energy Systems, 62: 273-283.

[4] Haghi, H. V., Bina, M. T., Golkar, M. A., \& Moghaddas-Tafreshi, S. M. 2010. Using Copulas for analysis of large datasets in renewable distributed generation: PV and wind power integration in Iran. Renewable Energy, 35(9): 1991 2000.

[5] Bilgen, S., Keleş, S., Kaygusuz, A., Sarı, A., \& Kaygusuz, K. 2008. Global warming and renewable energy sources for sustainable development: a case study in Turkey. Renewable and sustainable energy reviews, 12(2): 372-396. 
[6] Kaplan, Y. A. 2015. Overview of wind energy in the world and assessment of current wind energy policies in Turkey. Renewable and Sustainable Energy Reviews, 43: 562-568.

[7] Ilkılıç, C., Aydın, H., \& Behçet, R. (2011). The current status of wind energy in Turkey and in the world. Energy policy, 39(2): 961-967.

[8] Sklar. 1959. Fonctions de répartition à n dimensions et leurs marges. Publ. Inst. Statist. Univ. Paris, 229-231 .

[9] Genest, C., MacKay, J. 1986. The joy of copulas: Bivariate distributions with uniform marginals. The American Statistician, 40(4): 280-283.

[10] Genest, C., \& Rivest, L. P. 1993. Statistical inference procedures for bivariate Archimedean copulas. Journal of the American Statistical Association, 88(423): 1034-1043.

[11] Capéraà, P., Fougères, A. L., Genest, C. 1997. A nonparametric estimation procedure for bivariate extreme value copulas. Biometrika, 84(3): 567-577.

[12] Nelsen, R. B. 1997. Dependence and order in families of Archimedean copulas. Journal of Multivariate Analysis, 60(1): 111-122.

[13] R. B. Nelsen, (2006) An Introduction to Copulas, 2nd ed., Springer, New York.

[14] Genest, C., Favre, A. C. 2007. Everything you always wanted to know about copula modeling but were afraid to ask. Journal of hydrologic engineering, 12(4): 347-368.

[15] Genest, C., Nešlehová, J. 2007. A primer on copulas for count data. ASTIN Bulletin: The Journal of the IAA, 37(2): 475-515.

[16] Nelsen, R. B., Quesada-Molina, J. J., Rodríguez-Lallena, J. A., Úbeda-Flores, M. 2008. On the construction of copulas and quasi-copulas with given diagonal sections. Insurance: Mathematics and Economics, 42(2): 473-483.

[17] Genest, C., Rémillard, B., Beaudoin, D. 2009. Goodness-of-fit tests for copulas: A review and a power study. Insurance: Mathematics and economics, 44(2): 199-213.

[18] Bessa, R. J., Miranda, V., Botterud, A., Zhou, Z., \& Wang, J. 2012. Time-adaptive quantile-copula for wind power probabilistic forecasting. Renewable Energy, 40(1): 29-39.

[19] Bouyé, E., Salmon, M. 2013. Dynamic copula quantile regressions and tail area dynamic dependence in Forex markets. In Copulae and Multivariate Probability Distributions in Finance (pp. 125-154). Routledge.

[20] Lu, Q., Hu, W., Min, Y., Yuan, F., \& Gao, Z. 2014. Wind power uncertainty modeling considering spatial dependence based on pair-copula theory. In PES General Meeting| Conference \& Exposition, 2014 IEEE (pp. 1-5). IEEE.

[21] Zhang, N., Kang, C., Xia, Q., \& Liang, J. 2014. Modeling conditional forecast error for wind power in generation scheduling. IEEE Transactions on Power Systems, 29(3):1316-1324. 